\title{
How Much Are Biosimilars Used in Clinical Practice? A Retrospective Italian Population-Based Study of Erythropoiesis- Stimulating Agents in the Years 2009-2013
}

\author{
Ylenia Ingrasciotta $^{1} \cdot$ Francesco Giorgianni $^{1} \cdot$ Jenny Bolcato $^{2} \cdot$ Alessandro Chinellato $^{2} \cdot$ \\ Roberta Pirolo $^{2}$ - Daniele Ugo Tari ${ }^{3}$ - Chiara Troncone ${ }^{3}$ - Andrea Fontana ${ }^{4}$ - Valentina Ientile ${ }^{1}$. \\ Rosa Gini ${ }^{5}$ - Domenico Santoro ${ }^{1}$ Mariacarmela Santarpia $^{6} \cdot$ Armando Genazzani $^{7}$. \\ Ilaria Uomo ${ }^{8}$ - Maurizio Pastorello ${ }^{8}$ - Walter Sebastiano Pollina Addario ${ }^{9}$ - Salvatore Scondotto ${ }^{9}$. \\ Pasquale Cananzi ${ }^{10} \cdot$ Achille Patrizio Caputi $^{1} \cdot$ Gianluca Trifirò $^{1}$
}

Published online: 14 July 2015

(C) The Author(s) 2015. This article is published with open access at Springerlink.com

\begin{abstract}
Purpose To explore the prescription patterns of erythropoiesis-stimulating agents (ESAs) in four large Italian geographic areas, where different health policy interventions to promote biosimilar use in routine care are undertaken.

Methods A retrospective drug utilization study was conducted during the years 2009-2013. The data sources were the administrative databases of the Tuscany region and of the Caserta, Palermo, and Treviso Local Health Units (LHUs). The characteristics, prevalence, and switching patterns of different ESAs (biosimilars and reference products), stratified by indication for use, were calculated over time and across centers.

Results Overall, 49,491 patients were treated with ESAs during the years 2009-2013 in the four centers. Of these, 41,286 patients $(83.4 \%)$ were naive users. The prevalence of ESA use increased from 2.9 to 3.4 per 1000 inhabitants in the years 2009-2011 but decreased thereafter (3.0 per 1000 in 2013). Moreover, the proportion of biosimilar users
\end{abstract}

Electronic supplementary material The online version of this article (doi:10.1007/s40259-015-0132-7) contains supplementary material, which is available to authorized users.

Ylenia Ingrasciotta

ylenia.ingrasciotta@unime.it

Gianluca Trifirò

trifirog@unime.it

1 Department of Clinical and Experimental Medicine, University of Messina, Messina, Italy

2 Pharmaceutical Service, Local Health Authority (ULSS9), Treviso, Italy

3 Caserta-1 Local Health Service, Caserta, Italy

4 Unit of Biostatistics, IRCCS "Casa Sollievo della Sofferenza”, San Giovanni Rotondo, FG, Italy increased overall from $1.8 \%$ in 2010 to $33.6 \%$ in 2013 , with larger increase in Treviso (from 0.0 to $45.0 \%$ ) and Tuscany (from 0.7 to $37.6 \%$ ) than in Caserta (from 7.5 to $22.9 \%$ ) and Palermo (from 0.0 to $27.7 \%$ ). Switching between different ESAs during the first year of therapy was frequent $(17.0 \%)$, much more toward reference products than toward biosimilars.

Conclusion Overall, the prevalence of ESA use decreased slightly, while use of biosimilar ESAs, especially in naive patients, increased significantly but to different extents in these four large Italian geographic areas. Switching between different ESAs during the first year of treatment was very frequent, which may affect pharmacovigilance monitoring. New strategies are necessary to further improve market penetration of low-cost medicines, such as biosimilars, and also to harmonize effective health policy interventions that aim to reduce pharmaceutical expenses and optimize patient benefit across all regions.

\footnotetext{
Agenzia Regionale di Sanità della Toscana, Florence, Italy

6 Medical Oncology, Department of Human Pathology, University of Messina, Messina, Italy

7 Department of Pharmaceutical Sciences, “A. Avogadro", University, Novara, Italy

8 Department of Pharmacy, Palermo Local Health Unit, Palermo, Italy

9 Department of Epidemiologic Observatory, Health Department of Sicily, Palermo, Italy

10 Sicilian Regional Center of Pharmacovigilance, Servizio 7-Farmaceutica, Health Department of Sicily, Palermo, Italy
} 


\section{Key Points}

Overall, the prevalence of erythropoiesis-stimulating agent (ESA) use decreased slightly over the years in four large Italian geographic areas, while use of biosimilar ESAs, especially in naive patients, increased significantly but to different extents, most likely as a result of heterogeneous health policy interventions.

The proportion of biosimilar users increased overall from $1.8 \%$ in 2010 to $33.6 \%$ in 2013, with much larger increases in Treviso (from 0.0 to $45.0 \%$ ) and Tuscany (from 0.7 to $37.6 \%$ ) than in Caserta (from 7.5 to $22.9 \%$ ) and Palermo (from 0.0 to $27.7 \%$ ).

Switching between different ESAs during the first year of therapy was frequent $(17.0 \%)$, much more toward reference products $(84.1 \%$ of total switches) than toward biosimilars $(15.9 \%)$.

\section{Introduction}

The high cost of pharmaceuticals, especially biologics, has become an important issue for the sustainability of national health services [1].

Once the patent for a biologic expires, biosimilars can be developed, tested, and introduced into the market, after approval by regulatory agencies on the basis of a comparability exercise [2].

According to European Medicines Agency (EMA) guidelines, a biosimilar is "a biological medicinal product that contains a version of the active substance of an already authorized original biological medicinal product (reference medicinal product. A biosimilar demonstrates similarity to the reference medicinal product in terms of quality characteristics, biological, activity, safety and efficacy) based on a comprehensive comparability exercise" [3].

Several scientific societies have issued position papers on biosimilars, highlighting that, after many years since the introduction into the market of the first biosimilars, these drugs are to be considered as therapeutic equivalents of reference products. These views were based upon the absence of postmarketing data demonstrating significant differences in terms of safety or effectiveness between biosimilars and reference products. A recent position paper from the Italian Medicines Agency [Agenzia Italiana del Farmaco (AIFA)] recommends prescribing biosimilars to treat naive patients [e.g. patients never previously treated with erythropoiesis-stimulating agents (ESAs) or with previous exposure that is sufficiently distant in time]. However, the choice to treat a patient with a biologic reference product or a biosimilar is a clinical decision entrusted to the physician [4].

Since 2007, biosimilar ESAs have been authorized in the European Union, while only very recently was the first biosimilar approved by the US Food and Drug Administration (FDA). Epoetin alpha, which is mainly indicated to treat anemia associated with either chronic kidney disease (CKD) or chemotherapy in cancer patients, is one of a few biologics (in addition to filgrastim, somatropin, and, shortly, infliximab) for which biosimilars are currently available in Italy. The purchase costs of these biosimilars are 20-30 \% lower than those of the reference products [5].

From a public health perspective, epoetin alpha represents a test case for evaluation of the most effective strategies for promoting the use of biosimilars in clinical practice. In light of the expected marketing in the near future of several new biosimilars (e.g. etanercept, pegfilgrastim, and trastuzumab), it is imperative to evaluate the market penetration of currently available biosimilars, such as those of epoetin alpha. Such an analysis will allow tailoring of healthcare policy interventions to promote the use of biologics with the lowest costs in the near future [6].

To date, only sparse data on the use of biosimilar ESAs in the general Italian population are available. A retrospective drug utilization study documented very low consumption of biosimilar ESAs (0.9\% of total ESA use) in the Local Health Unit (LHU) of Messina in Southern Italy in the years 2010-2011 and very frequent switching between different ESAs ( $>20 \%$ of ESA users during the first 1.5 years of therapy), almost totally toward reference products [7].

Recently, consumption of biosimilar ESAs has been increasing to different extents in the various Italian regions. These regions follow different healthcare policy interventions and have introduced different legislatives rules. A national report on medicine use in Italy in 2013 showed that $41.0 \%$ of patients newly treated with epoetin alpha (i.e. epoetin alpha users without any prescription within the previous 6 months) were treated with biosimilars of epoetin alpha, with an increasing trend as compared with the previous years $(+71.6 \%)$ [8].

The aim of this population-based database study was to evaluate and compare, in the years 2009-2013, the prescribing patterns of biosimilar and reference product ESAs in four large Italian geographic areas, where different health policy interventions promoting biosimilar use were adopted. 


\section{Methods}

\subsection{Data Source}

This was an observational, retrospective, multi-database drug utilization study.

Fully anonymized data for this study were extracted from the administrative databases of the Tuscany region and the Caserta, Palermo, and Treviso LHUs, covering a total population of more than 6 million persons, during the years 2009-2013. Each LHU collects anonymized electronic data on ESA dispensing to residents in the catchment area. For each ESA prescription, specialists have to complete a therapeutic plan, which indicates the exact drug name, number of dispensed packages, dosing regimen, and indication for use. Electronic therapeutic plans were available in the Caserta and Treviso LHUs. These data can be linked through unique and anonymous patient identifiers to other claims databases, which contain several types of information, including causes of hospitalization and reasons for healthcare service co-payment exemptions. In all of the centers, drug dispensing is coded using the Anatomical Therapeutic Chemical (ATC) classification system, while indications for use and causes of hospitalizations are coded using the International Classification of Diseases, 9th revision, clinical modification (ICD9-CM). Information provided by the four centers is available in Electronic Supplementary Material (ESM) 1.

\subsection{Study Population}

For this study, all persons residing in the catchment areas of the Caserta and Treviso LHUs, as well as those in the Tuscany region, during the years 2009-2013 were considered. Concerning the Palermo LHU, data were available for the period 2011-2013. From the source population, we identified all patients with at least 1 year of database history and receiving at least one ESA dispensing during the study period.

\subsection{Study Drugs}

Use of the following ESAs during the study period was assessed: epoetin alpha (ATC: B03XA01; Eprex $^{\circledR}$, Abseamed ${ }^{\circledR}$, Globuren ${ }^{\circledR}$, Binocrit $\left.{ }^{\circledR}\right)$, epoetin beta (B03XA01; Neorecormon ${ }^{\circledR}$ ), darbepoetin alpha (B03XA02; Aranesp ${ }^{\circledR}, \mathrm{Nespo}^{\circledR}$ ), epoetin zeta (B03XA01; Retacrit ${ }^{\circledR}$ ), epoetin theta (B03XA01; Eporatio $\left.{ }^{\circledR}\right)$, and methoxypolyethyleneglycol-epoetin beta (B03XA03; Mircera $\left.{ }^{\circledR}\right)$. Binocrit ${ }^{\circledR}$, Abseamed ${ }^{\circledR}$, and Retacrit $^{\circledR}$ are biosimilars of epoetin alpha (see ESM 2). Binocrit ${ }^{\circledR}$, Retacrit $^{\circledR}$, Eprex $^{\circledR}$, Abseamed $^{\circledR}$, Globuren ${ }^{\circledR}$, Eporatio $^{\circledR}$, and Neorecormon ${ }^{\circledR}$ are first-generation ESAs; Nespo ${ }^{\circledR}$ and
Aranesp ${ }^{\circledR}$ are second-generation ESAs; and Mircera ${ }^{\circledR}$ is a third-generation ESA. Epoetin alpha, epoetin beta, darbepoetin alpha, and epoetin zeta have been specifically approved for treatment of anemia due to CKD in adult/pediatric patients, and for anemia induced by anticancer chemotherapy in adult patients. Epoetin theta has been approved to treat anemia due to CKD or induced by anticancer chemotherapy in adult patients, while methoxypolyethyleneglycol-epoetin beta has been approved only to treat anemia due to CKD in adults. The costs of epoetin alpha and beta for use in myelodysplastic syndromes are reimbursed by the Regional Health System in Italy, although this is not an approved indication.

\subsection{Healthcare Policy Interventions}

Italy has a tax-based, universal-coverage national health system, organized at a regional level. Healthcare policies can be included in regional regulations. Treviso belongs to the Veneto region, Caserta to the Campania region, and Palermo to the Sicily region. Tuscany is a region in itself. Different regional-based health policy interventions have been implemented over time. In 2009, Campania was the first region in Italy to impose use of biosimilars for firstchoice treatment of naive patients [9], followed by Tuscany [10] and Veneto [11] in 2010, and Sicily [12] in 2014. In ESM 3, we list the different healthcare policy interventions concerning the use of biosimilars that have been implemented in the four geographic areas.

\subsection{Data Analysis}

Fully anonymized data concerning ESA users were centrally aggregated and underwent quality control through benchmarking of different parameters across the four participating centers.

The index date was defined as the date of the first ESA dispensing in the study period.

For each ESA dispensing, information on the age and sex of the patient, the brand name of the drug, the dispensing date, the number of packages dispensed, and the cost of the drug was available. All drugs dispensed for each patient are linked through a unique and anonymous patient identifier.

\subsection{Characterization of ESA Users}

Naive ESA users (i.e. ESA users without any ESA dispensing in the year prior to the index date) identified in each database were characterized in terms of demographics and indication for use. ESA users were classified as biosimilar or reference product users on the basis of the ESA dispensing at the index date. On the basis of the 
information reported in the electronic therapeutic plan, the indication for use was categorized as follows: (i) CKD; (ii) cancer; or (iii) myelodysplastic syndrome.

In the absence of an electronic therapeutic plan, the indication for use was derived from hospital discharge diagnoses (ICD9-CM for cancer: $140^{*}-239^{*}$; ICD9-CM for CKD: 583*, 585*, 586*; ICD9-CM for myelodysplastic syndrome: $238.72-238.75)$ and reasons for healthcare service co-payment exemption (cancer: 048; CKD: 023), from the period before to 60 days after the index date. If categorization was still not possible, as a last step, ESA users were categorized by dose, such that those who received a prescription for low-dosage ESA (epoetins: $<30,000 \mathrm{IU} /$ $\mathrm{mL}$; darbepoetin alpha: $<80-100 \mathrm{mcg} / \mathrm{mL}$ ) at the index date were considered as CKD patients, while those receiving a high-dosage ESA prescription (epoetins: $\geq 30,000 \mathrm{IU} / \mathrm{mL}$; darbepoetin alpha: $\geq 80-100 \mathrm{mcg} / \mathrm{mL}$ ) were considered as cancer patients.

\subsection{Prevalence of ESA Treatment}

The overall and also center-specific crude and age-adjusted yearly prevalence of ESA users was calculated as rates per 1000 inhabitants, with $95 \%$ confidence intervals (CIs), using the number of patients with at least one ESA dispensing as the numerator, and using the number of residents in the catchment areas during the observation years as the denominator.

The frequency of biosimilar use over time and across centers among ESA users was also calculated.

At the index date, biosimilar ESA users were also distinguished as naïve users (no ESA dispensing within the previous year), prevalent users (at least one dispensing of the same ESA within the previous year), or switcher users (at least one prescription of a different ESA within the previous year).

All frequency analyses were stratified by the calendar year, center, and main indication for use (CKD or cancer).

\subsection{Switching Patterns}

Overall and center-specific analyses of the switching between different biosimilar and reference product ESAs that occurred during the first year of treatment after the index date were also performed. Switching between the same two ESAs was counted only once per patient, and only the first switch after the index date was taken into account. Globuren (epoetin alpha) users were grouped with Eprex users, while Nespo users were grouped with Aranesp users, as these products were co-marketed.

The switching patterns for different ESAs were graphically visualized using the software Cytoscape (http://www. cytoscape.org/).
All of the statistical analyses were conducted using SPSS/PC, Version 15 (SPSS Inc., Chicago, IL, USA). The level of significance for all statistical tests was set at $p<0.05$.

\subsection{Ethics Statement}

This study was conducted in the context of the "Assessment of Short and Long Term Risk-Benefit Profile of Biologics Through Healthcare Database Network in Italy" project, which was funded by the Italian Ministry of Health.

In agreement with current national law, the study protocol was submitted to the Ethical Committee of the Academic Hospital of Messina [13].

\section{Results}

During the study period, from a total population of 6,571,697 persons (more than $10 \%$ of the whole Italian population), 49,491 (0.8\%) received at least one prescription of ESA during the years 2009-2013 (Fig. 1). Of these, $41,286(83.4 \%)$ were naive users, who mostly started therapy with reference products $(N=32,430 ; 78.5 \%)$ and much less frequently with biosimilars $(N=8856 ; 21.5 \%)$ in all four centers. The age and sex distributions of biosimilar and reference product users were comparable (Table 1). Anemia due to CKD was the main reason for prescribing ESAs, mostly to elderly patients, irrespective of the ESA type, except in Tuscany, where $60 \%$ of patients started treatment with a biosimilar ESA to treat anemia induced by anticancer chemotherapy (Table 1).

The prevalence of total ESA use (Fig. 2) increased from 2.9 per 1000 inhabitants in 2009 to 3.4 per 1000 inhabitants in 2011, with a slight decrease in the following 2 years (3.0 per 1000 in 2013). A similar trend was observed in the ageadjusted analysis. Specifically, the prevalence of ESA use in the Caserta LHU was higher during the first 4 years of the study (1.6-2.1 per 1000 inhabitants in 2009-2012, decreasing thereafter [1.8 per 1000 inhabitants in 2013]) than in the Treviso and Palermo LHUs and in Tuscany (see ESM 4). The patterns of ESA use did not change with stratification by indication for use (see ESM 5), except in Caserta, where an increase in the prevalence of ESA use in cancer patients during the study years was found. Overall, an increase in the proportion of ESA users receiving biosimilars in the four geographic areas over time was observed (Fig. 3), ranging from $1.8 \%$ of total ESA users in 2010 to $33.6 \%$ in 2013, with much larger increases in Treviso (from 0.0 to $45.0 \%$ ) and the Tuscany region (from 0.7 to $37.6 \%$ ) than in Caserta (from 7.5 to $22.9 \%$ ) and Palermo (from 0.0 to $27.7 \%$ ). A similar trend was observed when the analysis was stratified by indication for 


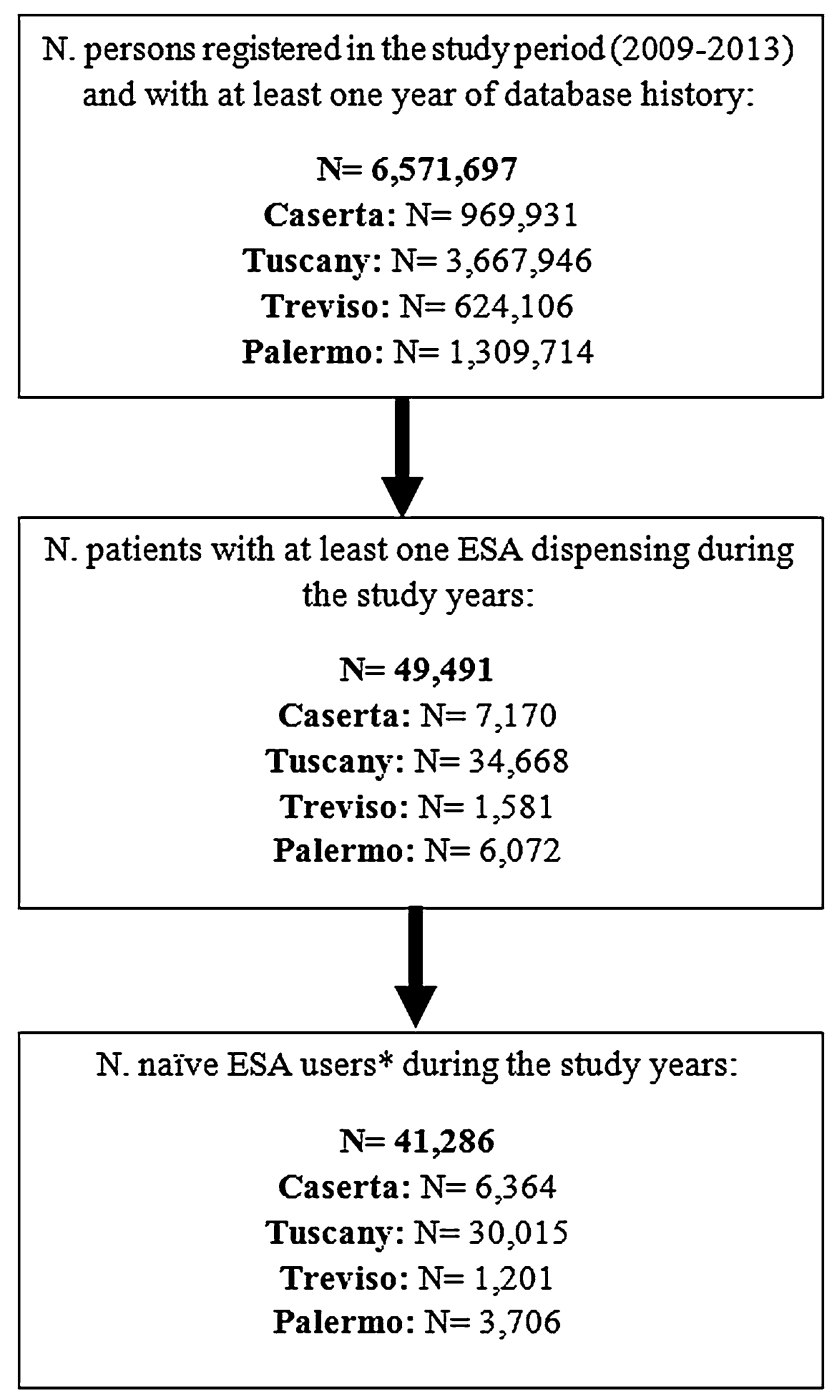

Fig 1 Identification of erythropoiesis-stimulating agent (ESA) users in the four centers. Asterisk naive ESA users: ESA users without any ESA dispensing in the year prior to the index date, $N$ number

use; biosimilars were most frequently prescribed to treat anemia due to anticancer chemotherapy in the four geographic areas, with a slight decrease in the Caserta LHU during the last study year $(19.5 \%$ in 2013 as compared with $27.6 \%$ in 2012) (see ESM 6). Most biosimilar users were naive patients (Fig. 4). Darbepoetin alpha (Aranesp) and epoetin zeta (Retacrit) were the most frequently prescribed ESAs among reference products and biosimilars, respectively. Epoetin zeta (a biosimilar of epoetin alpha) prescriptions increased substantially from 2009 to 2013 (from 0 to $18 \%$ in Palermo, from 0 to $21 \%$ in Caserta, from 0 to $24.0 \%$ in the Tuscany region, and from 0 to $38.0 \%$ in Treviso) (see ESM 7).

In Fig. 5, the switching patterns across different ESAs during the first year of treatment after the index date are shown. Switching between different ESAs was very frequent $(17.0 \%)$. Among switchers, ESA users switched more frequently toward a reference product $(84.1 \%)$ than toward a biosimilar $(15.9 \%)$. ESA users switched more frequently to Eprex (29.4\% of total switchers), which is the reference product of epoetin alpha. In addition, switches from Binocrit to Eprex occurred in $27.6 \%$ of Binocrit users in Palermo, in $18.9 \%$ of those in Tuscany, in only $6.7 \%$ of those in Treviso, and in none of those in Caserta.

Taking into account all of the ESAs together, of a total of 4006 switchers (17.0 \%) between different ESAs, 398 ESAs users $(9.9 \%)$ switched to Mircera.

Of the total switches between different ESAs, $42.3 \%$ were between different first-generation ESAs, $19.3 \%$ were from first-generation to second-generation ESAs, and $19.8 \%$ were from second-generation to first-generation ESAs.

\section{Discussion}

To our knowledge, this is the first population-based study analyzing the patterns of use of biosimilar ESAs over a long study period and in a large cohort of Italian outpatients from different geographic areas.

Overall, our results show that ESAs were mostly prescribed for treatment of anemia due to CKD; however, in the Tuscany region, biosimilars were mostly used to treat anemia induced by anticancer chemotherapy $(N=3678$; $60.1 \%$ of naive biosimilar users). The proportion of ESA users who received biosimilars increased considerably in all four Italian geographic areas from 2009 to 2013, despite the overall use of ESAs reducing slightly in 2012-2013. A high degree of heterogeneity of ESA use across different Italian regions was observed in a previous Italian paper [14], in line with our results. The different extent of biosimilar ESA use was probably due to differences in dates of issuing and the content of healthcare policy interventions. Moreover, potential regional differences in marketing of the different ESAs by pharmaceutical companies, as well as clinicians' skepticism about the actual comparability of the benefit-risk profiles of the biologic reference products and corresponding biosimilars, may have partly contributed to the heterogeneity of ESA use in Italy.

In 2009, Campania (Caserta) was the first Italian region to issue healthcare policy interventions promoting biosimilar use in naive patients [9]. This probably explains the much higher proportion of ESA users treated with biosimilars in Caserta as compared with the other three centers (Treviso, Palermo, and Tuscany) in 2010. Furthermore, while the trend became stable in Caserta in the following years, larger increases in the proportions of biosimilar users in Palermo, Treviso, and Tuscany were 


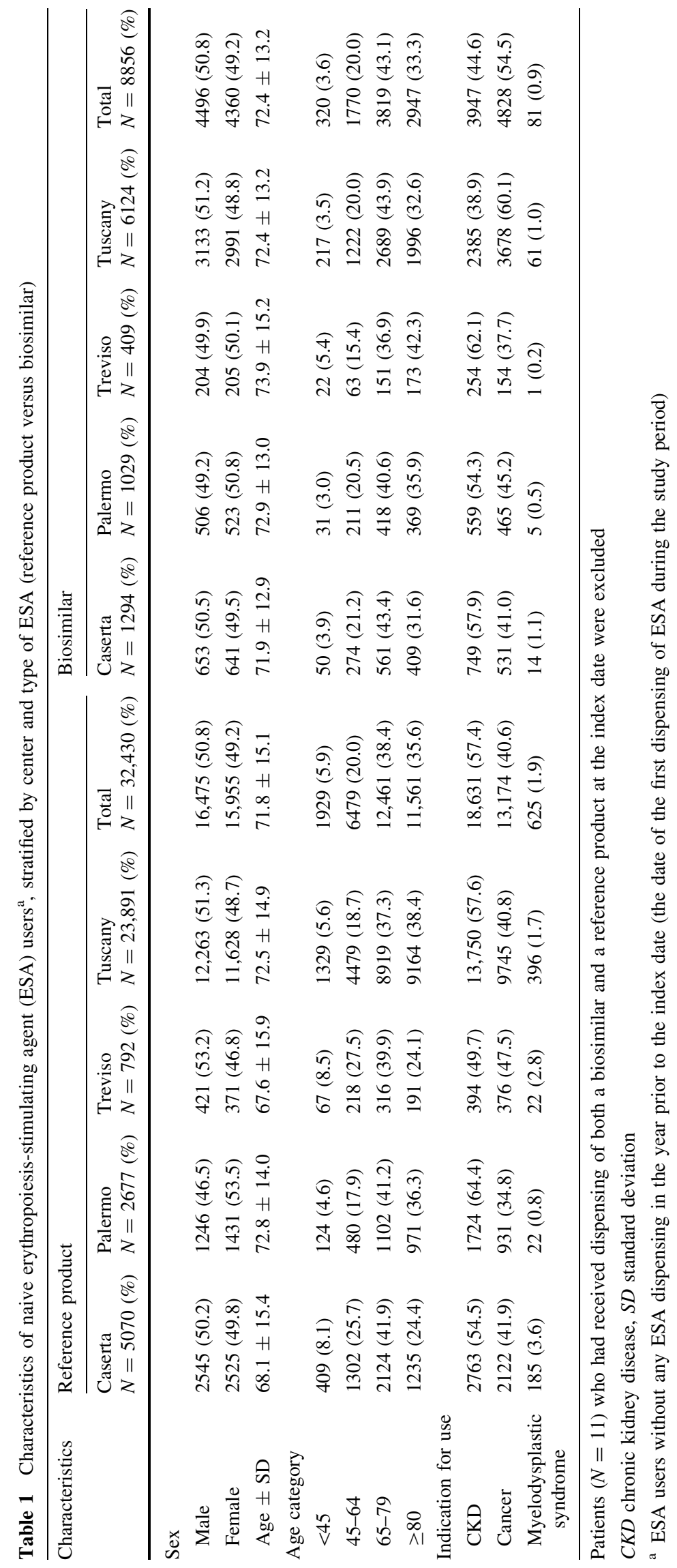


Fig 2 Crude prevalence of (ESA) users per 1000 inhabitants, stratified by calendar year and center erythropoiesis-stimulating agent

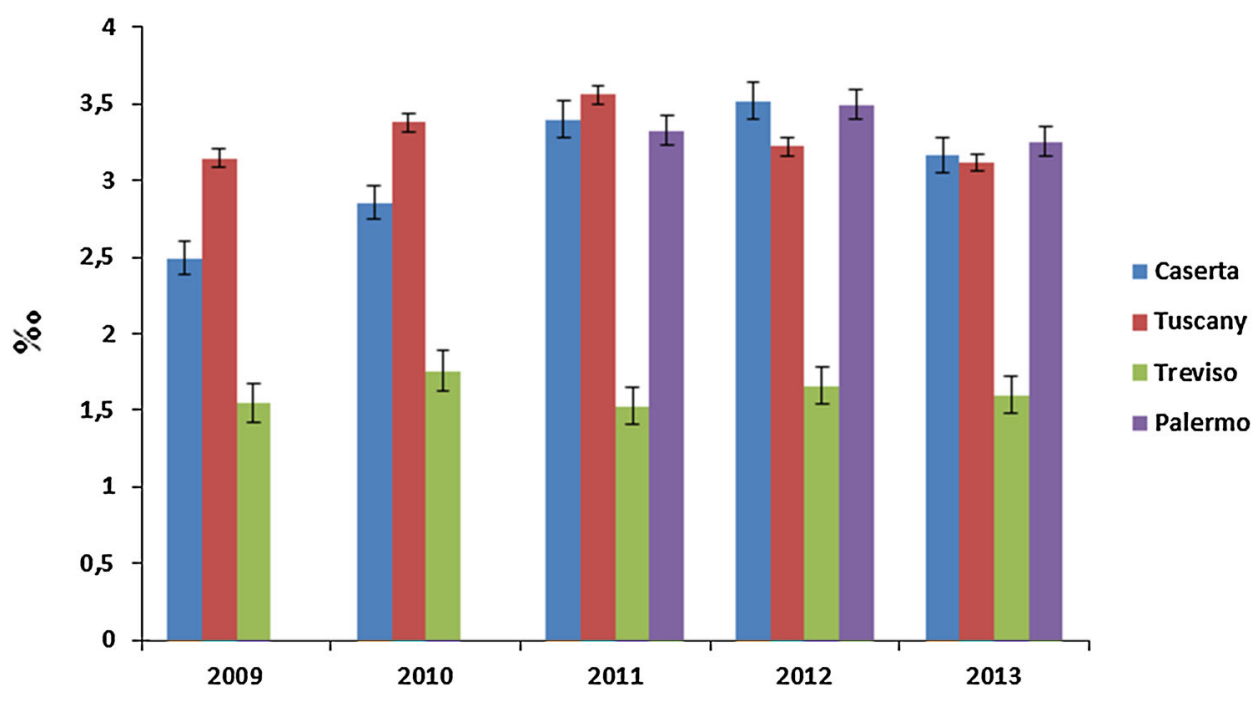

Fig 3 Percentages of biosimilar users out of the total numbers of erythropoiesis-stimulating agent (ESA) users, stratified by calendar year and center

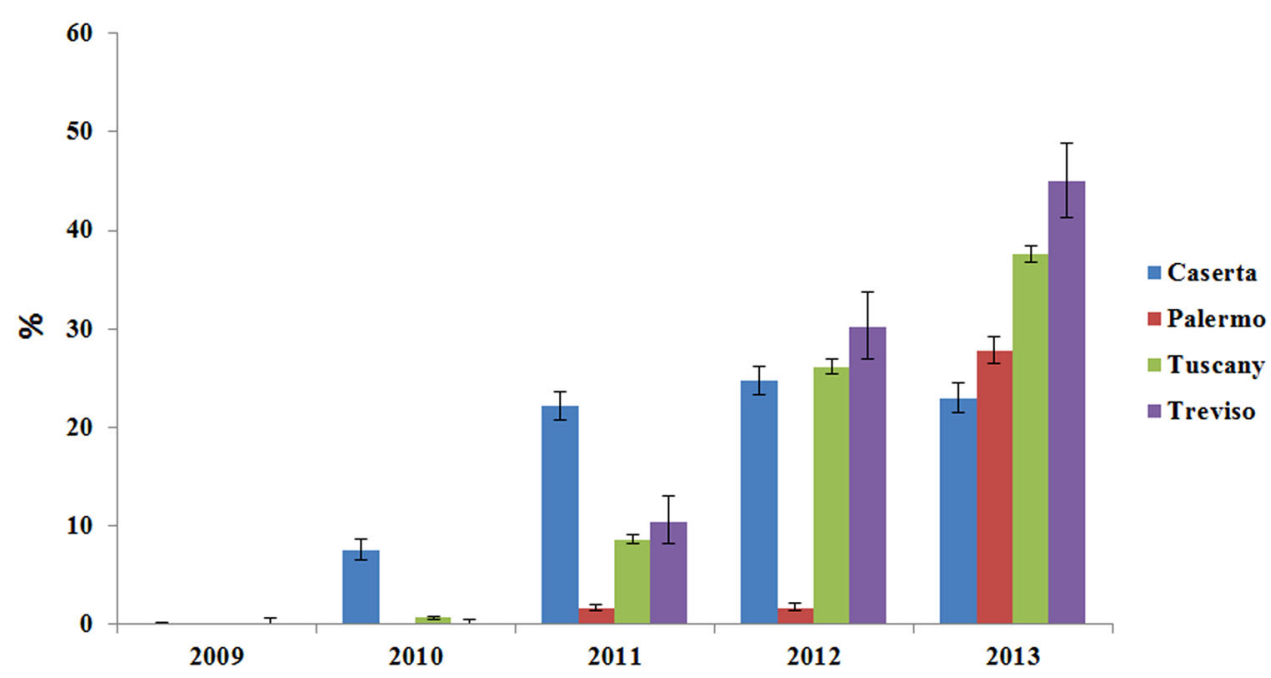

observed, very likely as a result of more stringent recommendations for use of biosimilars in routine care.

In particular, in 2010 in Tuscany and Veneto, and only in 2012 and 2014 in Campania and Sicily, respectively, the regional governments made it mandatory for ESA prescribers to document the reason why a drug other than a biosimilar is chosen. This must be done using a dedicated electronic form, which is then sent online to the LHU [10, $11,15,16]$. This is a measure to guarantee cost saving and to ensure the efficacy and safety of the therapy.

Apart from regional-based regulations, it is probable that skepticism on the part of clinicians as a result of limited information about biosimilars may have contributed to the observed heterogeneity in biosimilar market penetration, indicating the need for more effective educational interventions.

The study results confirm that most biosimilar users were naive patients, and only a very small proportion represented reference product ESA users switching toward a biosimilar.

In fact, during the first year of therapy, switching between different ESAs was very frequent, mostly toward reference products $(84.1 \%$ of total switchers) rather than toward biosimilars $(15.9 \%)$. This is in line with the findings of a recent drug utilization study, which was conducted in the LHU of Messina in Southern Italy [7].

Debate is still ongoing about the substitution of reference products with biosimilar ESA therapy in patients already in treatment. For a variety of reasons, substitution is not recommended for biologics. Decisions on substitution depend on the single national authority [17]. According to the Medicines Evaluation Board (MEB), exchanges between biologics (regardless of whether they are innovator products or biosimilars) are permitted, but only if adequate clinical monitoring is performed and the patient is properly informed [18]. However, in Italy, the position 


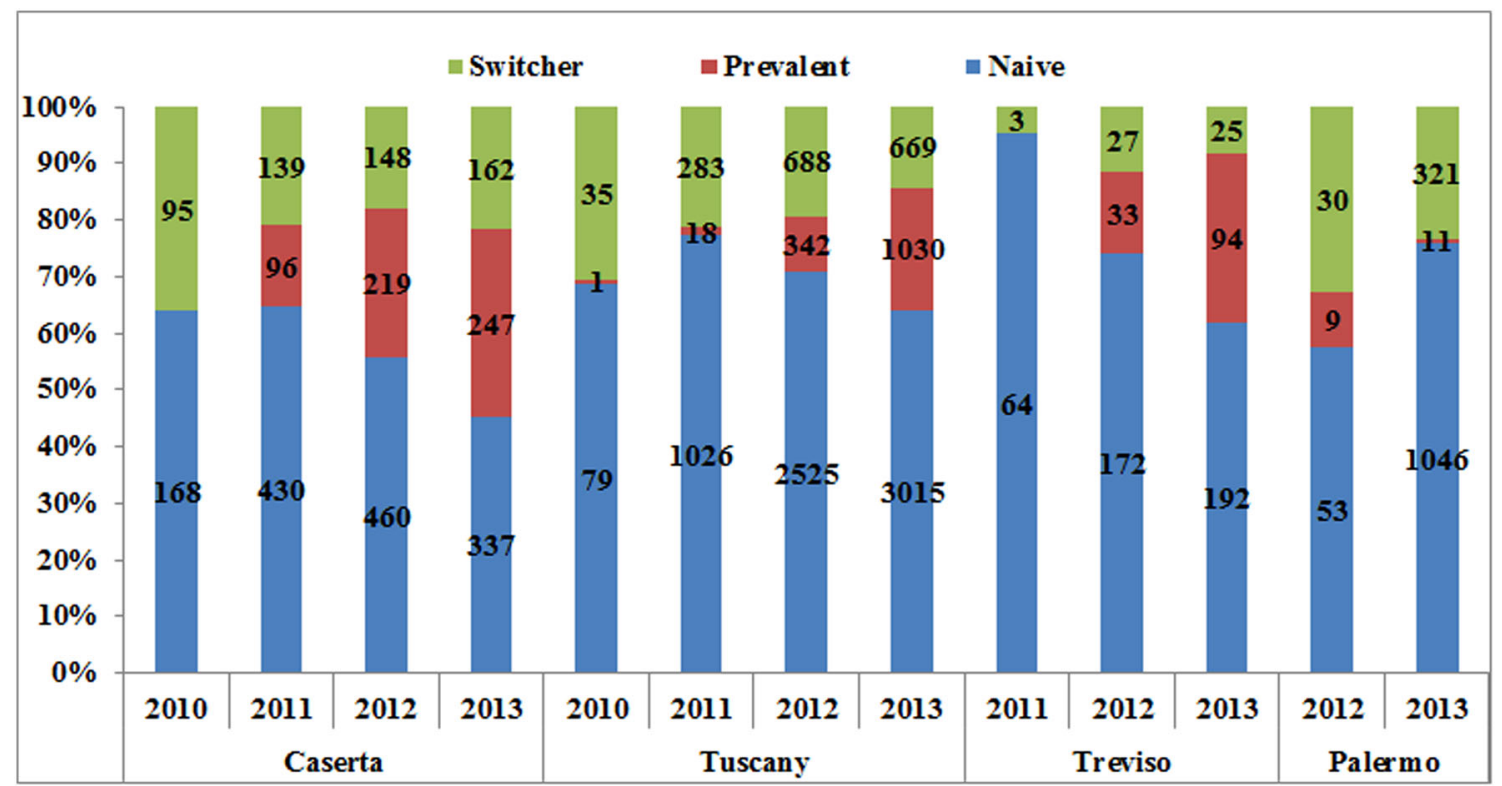

Fig 4 Prescribing patterns of biosimilar erythropoiesis-stimulating agent (ESA) users, stratified by calendar year and center. "Naive" means no ESA dispensing within the previous year, "Prevalent" means only the same biosimilar dispensing within the previous year, and "Switcher" means at least one dispensing of a different ESA within the previous year. The numbers shown inside each bar represent the numbers of naive, prevalent, and switcher users. 1 year of database history before each year in the graph should be available, so it was not possible to evaluate use in the year 2011 in the Palermo Local Health Unit (LHU)

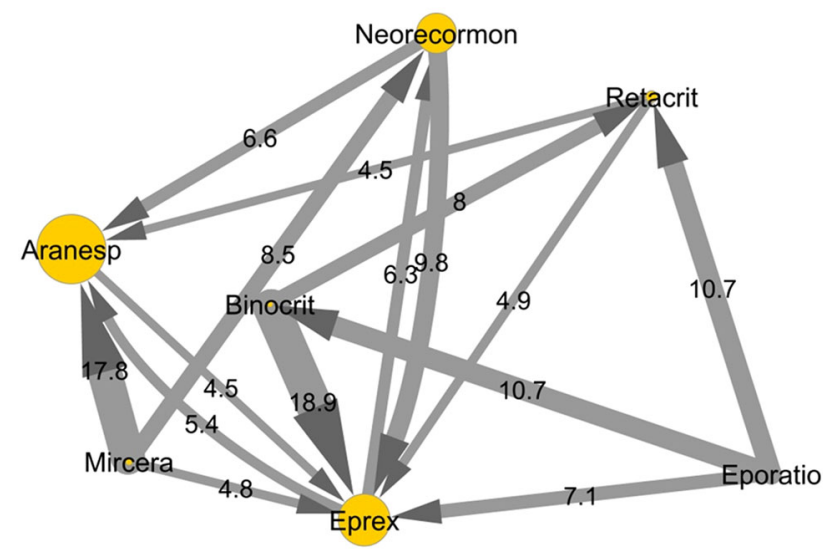

Fig. 5 Switching patterns of erythropoiesis-stimulating agents (ESAs) during the first year of treatment after the index date in all of the centers. The size of each node indicates the number of users; the size of each arrow indicates the proportion of users (minimum $4 \%$ ) who switched between one product and another; switching was counted only once per patient, and only the first switch after the index date was considered. Globuren users were grouped with Eprex users, and Nespo users were grouped with Aranesp users. Abseamed was not included in this figure because there were no switchers

paper of the AIFA excludes automatic therapeutic substitution of reference products with biosimilars [4].

A retrospective study explored the impact of switching from epoetin alpha to epoetin zeta, or vice versa, in patients with CKD on dialysis, showing that epoetin alpha and epoetin zeta therapy can be interchanged without any clinically significant alteration in efficacy, safety, or epoetin dose [19]. Switching between different ESAs during the first year of treatment was very frequent, which may affect pharmacovigilance monitoring. The high frequency of switching between various ESAs is likely to be attributed to either ineffectiveness (missed achievement of a therapeutic goal, i.e. a predefined hemoglobin threshold), tolerability, or physician/patient preference due to differences in the frequency or route of administration between various ESAs, which may affect patient compliance [20].

An additional issue to be considered regarding frequent switching between different ESAs concerns the difficulty of performing pharmacovigilance monitoring. If an adverse event occurs after a switch from one biologic to another without documentation of the product change, the event would not be able to be linked to a specific product during pharmacovigilance assessment, or it could be ascribed to the wrong product. Traceability is important in postmarketing surveillance of biologics, since changes in the manufacturing process may give rise to product- or batchspecific risks. However, spontaneous reporting systems (SRSs) are not considered valid sources to ensure traceability, because of the manual nature of data transfer. The product traceability of biologics is routinely ensured within the individual patient's pharmacy records; while variable product information, such as the product batch number, 
is-conversely-expected to be infrequently captured in dispensing records at present [21]. An Italian study [22] using the national SRS database explored adverse drug reaction (ADR) reports attributed to biosimilars/reference products in Italy during the period 2001-2013. Out of a total of 171,201 collected ADR reports, 9601 (5.6\%) were related to biologic products, and of those, $135(1.4 \%)$ were related to biosimilars. Traceability of biologics was evaluated on the basis of the presence of the batch number and the brand name of the suspect drugs in the reports. Overall, an identifiable brand name was indicated in $94.8 \%$ of biologic-related reports, while a batch number was present in only $8.6 \%$ of reports. A higher level of completeness was available for those biologics with expired patents (brand name of product present in $98.7 \%$ of reports; batch number in $13.4 \%$ ).

\subsection{Strengths and Limitations}

The main strength of this population-based study is the possibility to explore the data on ESA dispensing from four large geographic areas for a period of 5 years. As the first biosimilar ESAs were introduced into the market in Italy in 2007, we were able to explore the effect of biosimilar marketing on the prescribing patterns of ESAs, and also in relation to different healthcare policy interventions. Availability of an electronic therapeutic plan provides information on the exact brand name, number of dispensed packages, and indication for use; at the time when the analyses were carried out, the electronic therapeutic plan was available only in Treviso and Caserta.

Data concerning the Palermo LHU were available only for the years 2011-2013.

All databases provide information on the costs of ESA, but this information changes across centers, distribution channels, and calendar years; however, biosimilar ESAs were, in general, 20-30\% less expensive than reference products.

Some ESA dispensing might not have been captured by the LHU databases (i.e. the first therapeutic cycle of an ESA), as drugs are dispensed directly in the hospital. However, it is unlikely that this limitation affected the study results.

Finally, our findings may not be fully generalized to the whole Italian general population, as the study was restricted to four large geographic areas from Southern, Central, and Northern Italy; however, the comparison with the Italian national report on drug consumption supported the reliability of these databases in providing information about ESA use in the Italian outpatient setting.

\section{Conclusion}

Recently, the use of biosimilar ESAs, especially in naive patients, has increased significantly but to different extents in four large Italian geographic areas, most likely as a result of heterogeneity in regional health policy interventions promoting biosimilar use. Switching between different ESAs was frequent; however, it was only rarely toward biosimilars, thus potentially affecting pharmacovigilance monitoring and raising questions about the interchangeability of different ESAs. In light of the expected marketing of a broad range of biosimilars in the near future, strategies to facilitate the widespread use of biologics with the lowest costs should be developed, and their impact should be assessed throughout various Italian regions, with the ultimate goal being to ensure the sustainability of the national health service.

Acknowledgments This study was conducted in the context of the "Assessment of Short and Long Term Risk-Benefit Profile of Biologics Through Healthcare Database Network in Italy" project, which was funded by the Italian Ministry of Health. None of the results presented in the current manuscript have been published elsewhere.

Author contributions All authors made substantial contributions to the conception or design of the work and/or to the acquisition, analysis, or interpretation of the data. All authors were involved in developing and critically revising the content of the manuscript, and all provided final approval of the version submitted for publication.

\section{Compliance with Ethical Standards}

Conflicts of interest The authors declare that they have no conflicts of interest.

Ethical approval This manuscript does not contain clinical studies or patient data. For this type of study, formal consent is not required.

Open Access This article is distributed under the terms of the Creative Commons Attribution-NonCommercial 4.0 International License (http://creativecommons.org/licenses/by-nc/4.0/), which permits any noncommercial use, distribution, and reproduction in any medium, provided you give appropriate credit to the original author(s) and the source, provide a link to the Creative Commons license, and indicate if changes were made.

\section{References}

1. Blackstone EA, Fuhr JP. The economics of biosimilars. Am Health Drug Benefits. 2013;6(8):469-78.

2. Ventola CL. Biosimilars: part 1 . Proposed regulatory criteria for FDA approval. Pharm Ther. 2013;38(5):270-87.

3. European Medicines Agency. Committee for Medicinal Products for Human Use (CHMP): guideline on similar biological medicinal products containing biotechnology-derived proteins as 
active substance: non-clinical and clinical issues. Available from: http://www.ema.europa.eu/docs/en_GB/document_library/ Scientific_guideline/2013/06/WC500144124.pdf.

4. Agenzia Italiana del Farmaco (AIFA). Position paper sui farmaci biosimilari (28/05/2013). Available from: http://www. agenziafarmaco.gov.it/sites/default/files/AIFA_POSITION_PAPER_ FARMACI_BIOSIMILARI.pdf.

5. Genazzani AA, Biggio G, Caputi AP, et al. Biosimilar drugs: concerns and opportunities. Biodrugs. 2007;21:351-6.

6. Assogenerici. Biosimilari. Available from: http://www.assogenerici. org $/ 2011 /$ biosimilari.asp? $s=2 \& p=1 \&$ modulo=biosimilari.

7. Loiacono C, Sgroi C, Coppolino S, et al. How much are biosimilars used in southern Italy? A retrospective analysis of epoetin utilization in the Local Health Unit of Messina in the years 2010-2011. Biodrugs. 2012;26:113-20.

8. Agenzia Italiana del Farmaco (AIFA). L'uso dei farmaci in Italia-rapporto OsMed 2013. Available from: http://www. agenziafarmaco.gov.it/it/content/luso-dei-farmaciitalia-rapportoosmed-2013.

9. Decreto Commissariale (DC) n. 15: "Piano di contenimento della spesa farmaceutica ospedaliera". 30/11/2009. Available from: http://www.aiopcampania.it/public/normativa/decreto_15_ deliberazioni_del_commissario_ad_acta.pdf.

10. Decreto n. 592: "Farmaci biosimili: direttive alle aziende sanitarie ed agli Enti per i Servizi Tecnico-Amministrativi di Area Vasta (ESTAV) della Regione Toscana”. 07/06/2010. Available from: http://web.rete.toscana.it/burt/?LO=01000000d9c8b7a6030 000000f000000514300000a8a5340000000000100481000000000 0000000000000000000000000000000000000000000000000000 00000000000000000000\&MItypeObj=application/pdf.

11. Linee guida per l'impiego e l'acquisto dei farmaci biosimilari: parere espresso dalla Commissione Terapeutica del Prontuario Terapeutico Ospedaliero regione Veneto (PTORV). 11/11/2010.

12. D.A n. 804. 3/05/2011. Rete Regionale dei Centri Prescrittori. Available from: http://www.gurs.regione.sicilia.it/Gazzette/g1142/g11-42.pdf.

13. Ministero della Salute, Agenzia Italiana del Farmaco (AIFA). Circolare AIFA del 3 agosto 2007. Linee guida per la classificazione e conduzione degli studi osservazionali sui farmaci. Available from: http://xoomer.virgilio.it/pgiuff/osservazionali.pdf.

14. La Vecchia C, Franceschi S, Apolone G. Drug distribution and expenditure: the issue of epoetin in Italy. Eur J Public Health. 2003;13(4):367.

15. Decreto n. 34: "Incentivazione dell'uso dei farmaci biosimilari. Razionalizzazione del File F dei farmaci oncologici ad alto costo". 20/03/2012. Available from: http://burc.regione.campania.it/ eBurcWeb/BurcPdfOutput/Burc_2012_3_26_14_8.pdf.

16. D.A. n. 540/14 Misure volte a promuovere l'utilizzo dei farmaci originatori o biosimilari a minor costo di terapia del 2/04/2014. Available from: http://pti.regione.sicilia.it/portal/page/portal/PIR PORTALE/PIR_LaStrutturaRegionale/PIR_AssessoratoSalute/PIR_ Decreti/PIR_Decreti2014/PIR_Provvedimentiorganiindirizzopolitico/ Decreto\%20sull'utilizzo\%20dei\%20farmaci\%20biosimilari.pdf.

17. European Medicines Agency. EMA procedural advice for users of the centralised procedure for similar biological medicinal products applications. Available from: http://www.ema.europa. eu/docs/en_GB/document_library/Regulatory_and_procedural_ guideline/2012/04/WC500125166.pdf.

18. Medicines Evaluation Board (MEB). Available from: http:// www.cbg-meb.nl/CBG/en/human-medicines/medicinal+products/ biosimilars/Are-biosimilar-medicinal-products-interchangeable/ default.htm.

19. Więcek A, Ahmed I, Scigalla P, Koytchev R. Switching epoetin alfa and epoetin zeta in patients with renal anemia on dialysis: posthoc analysis. Adv Ther. 2010;27(12):941-52. doi:10.1007/ s12325-010-0080-z.

20. Lonnemann G, Wrenger E. Biosimilar epoetin zeta in nephrology-a single dialysis center experience. Clin Nephrol. 2011;75(1):59-62.

21. Vermeer NS, Spierings I, Mantel-Teeuwisse AK, et al. Traceability of biologicals: present challenges in pharmacovigilance. Expert Opin Drug Saf. 2015;14(1):63-72.

22. Cutroneo PM, Isgrò V, Russo A, et al. Safety profile of biological medicines as compared with non-biologicals: an analysis of the Italian spontaneous reporting system database. Drug Saf. 2014;37:961-70

23. Decreto Commissariale n. 44: "Misure di controllo della spesa farmaceutica". 14/07/2010. Available from: http://www.aslcaserta. it/portale/Portals/0/doc_pub/2012/ATTIREGIONE/dca_44_Misure\% 20di\%20controllo\%20spesa\%20farmaceutica.pdf.

24. Decreto n. 27: "Misure di incentivazione della prescrizione di farmaci a brevetto scaduto e dei farmaci biosimilari". 15/03/ 2013. Available from: http://burc.regione.campania.it/eBurcWeb/ publicContent/archivio/archivio.iface\#2.PARTE SECONDA ATTI DELLO STATO E DI ALTRI ENTI PUBBLICI.

25. Decreto n. 114: Modifiche e integrazioni del DC n. 25 del 14.03.2012 "Individuazione/Aggiornamento Rete Regionale dei Centri prescrittori e codifica-monitoraggio induzione spesa farmaceutica 02/12/2013. Available from: http://burc.regione. campania.it/eBurcWeb/publicContent/archivio/archivio.iface.

26. Deliberazione della Giunta Regionale n. 2369: "Integrazione obiettivi per l'anno 2012 alle Aziende ULSS del Veneto, all'Azienda Ospedaliera di Padova, all'Azienda Ospedaliera Universitaria Integrata di Verona e all'IRCCS Istituto Oncologico Veneto". 29/12/2011. Available from: http://bur.regione.veneto. it/BurvServices/Pubblica/DettaglioDgr.aspx?id=236998.

27. Linee di indirizzo per l'appropriatezza prescrittiva dei farmaci nelle Aziende ULSS della Regione Veneto. 20/05/2013.

28. Prontuario Terapeutico Ospedaliero-Territoriale della Regione Siciliana (PTORS). Allegato al D.A. n. 01718 del 15/09/2011. Available from: http://pti.regione.sicilia.it/portal/page/portal/ PIR_PORTALE/PIR_LaStrutturaRegionale/PIR_Assessorato Salute/PIR_DipPianificazioneStrategica/PIR_DPSServizio7News/ Allegato\%20al\%20DA\%201718\%20del\%2015-09-2011.pdf.

29. Notifica delle decisioni della Commissione Regionale per il Prontuario Terapeutico Ospedaliero/Territoriale della Regione Sicilia Prot. n. 30449 del 29/03/2013. Available from: http:// pti.regione.sicilia.it/portal/page/portal/PIR_PORTALE/PIR_La StrutturaRegionale/PIR_AssessoratoSalute/PIR_DipPianificazione Strategica/PIR_DPSServizio7News/Notifica\%20decisioni\%20 seduta\%20de1\%2019-3-2013.pdf.

30. D. A. Approvazione dell'Accordo per la Distribuzione per conto (DPC) dei farmaci inclusi nel prontuario terapeutico ospedaliero (PHT) del 8/01/2014. Available from: http://sanita.e-shark.it/ downloads/aggiornamenti/DPC_D.A.8.1.14.pdf.

31. D. A. n. 540/14 Misure volte a promuovere l'utilizzo dei farmaci Originatori o Biosimilari a minor costo di terapia. Circolare esplicativa del 28/04/2014. Available from: http://pti.regione. sicilia.it/portal/page/portal/PIR_PORTALE/PIR_LaStruttura Regionale/PIR_AssessoratoSalute/PIR_Circolari/PIR_circolarianno 2014/Circolare\%20esplicativa\%20sull'utilizzo\%20dei\%20farmaci\% 20originat.pdf.

32. D. A. n. 540/14 "Misure volte a promuovere l'utilizzo di Farmaci Originatori o Biosimilari a minor costo di terapia". Chiarimenti del 17/06/2014.

33. Farmaci a PHT in distribuzione per conto. Regione Sicilia. 04/08/ 2014. Available from: http://www.ordinemedicipa.it/upload/ Allegato_1840.pdf. 